ЖӘанов С. М. Язык, мышление и «глубинные истины» // Философия. Журнал Высшей школы экономики. - 2018. - Т. II, № 4. - С. 107-115.

\title{
СЕРГЕЙ ЖААНОВ*
}

\section{ЯзЫК, МЫшлЕНИЕ И «ГлУБИНныЕ иСТИНЫ»**}

DOI: $10.17323 / 2587-8719-2018-I I-4-107-115$.

В своей интересной и интригующей статье «(Без)думные твари» Юлия Горбатова предлагает собственный взгляд на проблему соотношения языка и мышления. Двумя сквозными мотивами в ее рассуждениях выступают сравнение человеческого мышления с мышлением животных, а также пронизанная экзистенциалистскими реминисценциями идея не опосредованного языком доступа к «глубинным» истинам. Именно эта последняя идея становится, в конечном итоге, главной посылкой аргумента в пользу несводимости человеческого мышления к языку, тогда как вопрос о мышлении животных оказывается своеобразным ложным следом: не исключено, что животные имеют иную психологию, и, быть может, тоже имеют свой особый выход к «глубинным» истинам, но вряд ли нам когда-либо удастся установить данный факт с достоверностью.

Я разделяю тезис о несводимости мышления к языку, хотя считаю истинность этого тезиса совместимой с невозможностью невербализуемого мышления. Редукция мышления к языку всего лишь предполагает производность содержания психологических состояний от содержания языковых выражений, а редукция в обратном направлении предполагает обратную зависимость между языковым и психологическим содержанием. Сам по себе вопрос о вербализуемости мышления я оставляю открытым, поскольку являюсь агностиком в отношении существования неконцептуального интенционального содержания. Тем не менее, я уверен, что мышление о «глубинных» истинах не может служить примером невербализуемого мышления, в пользу чего привожу аргументы в первой части настоящего комментария. Вторая часть комментария посвящена краткому изложению моего понимания тезиса о несводимости мышления к языку.

*Жданов Сергей Михайлович, независимый исследователь, sergei@zhdanov.co.

** (C) Жданов, С. М. (C) Философия. Журнал Высшей школы экономики. 
Я сомневаюсь, что при обсуждения языка и мышления должны играть какую-либо роль так называемые «глубинные» истины (а также другие экзистенциалистские общие места, такие как «просвет бытия», «подлинное существование», мысли о смерти и проч. ${ }^{1}$ Мои сомнения носят как методологический, так и содержательный характер; остановимся по очереди на тех и на других.

Методологические сомнения касаются в первую очередь языка экзистенциальной философии, особенность которого состоит в том, что он, мягко говоря, не изобилует дефинициями, дистинкциями и доказательствами, а, напротив, довольно герметичен и метафоричен. Сам по себе данный факт еще не означает, что такая философия не заслуживает внимания. K примеру, доктрины Витгенштейна в той или иной мере обладают всеми приведенными характеристиками, однако они, без сомнения, имеют значительную философскую ценность, являясь важным источником вдохновения для многих поколений философов, включая современных. Отличие философии Витгенштейна от экзистенциализма проявляется, по моему мнению, в характере вторичной философской литературы. Современные витгенштейнианцы часто озабочены прояснением, уточнением или даже интерпретацией мыслей Витгенштейна, что ведет к появлению новых содержательных философских теорий, отвечающих современным научным стандартам и выступающих как серьезные попытки решения актуальных философских проблем². Вторичная литература по экзистенциализму, с другой стороны, отмеченной особенностью не обладает. В частности, гораздо реже встречаются попытки переложить содержание экзистенциалистской философии на более строгий академический язык ${ }^{3}$. Создается впечатление, что большинство современных авторов, работающих в парадигме экзистенци-

${ }^{1}$ Все приведенные примеры, разумеется, ведут родословную из творчества одного отдельного человека (Хайдеггера), однако, учитывая их популярность, а также возможность подобного рода терминов другого авторства, кажется более уместным использовать общее название - «экзистенциализм».

${ }^{2}$ Сказанное, разумеется, не означает, что таковы все витгенштейнианские доктрины. Исключением как раз является, например, витгенштейнианская точка зрения относительно соотношения языка и мышления.

${ }^{3}$ Еще более редки исследования, касающиеся не частных аспектов учений обсуждаемых философов, а фундаментальных положений наподобие тех, что обсуждаются в настоящем комментарии. 
альной философии, прибегают примерно к тому же языку, которым оперировали ее отцы-основатели.

Аргументом в пользу отмеченного status quo в экзистенциалистской литературе могла бы служить (и часто служит по факту) ссылка на невозможность перевода содержания развиваемого в ней философского учения на стандартный академический язык. Действительно, не может ли быть такого, что все прочие области знаний, а также повседневная речь просто-напросто не имеют словаря, необходимого для выражения особых истин о реальности, открываемых перед нами экзистенциальной философией? ${ }^{4} \mathrm{~K}$ идее такого рода я отношусь крайне скептически. Прежде всего, существуют косвенные соображения против самой возможности ограничений языка того типа, к которым апеллирует приведенный аргумент. Язык позволяет строить описания практически любой длины и сложности и ссылаться при этом на различные характеристики обсуждаемых сущностей. Описание может иметь родовидовую структуру, может выделять внутренние либо относительные свойства вещей, может опираться на аналогию с чем-то хорошо известным, может выстраиваться с помощью примеров. Даже если согласиться, например, что содержание фигуративной речи, которой так насыщена экзистенциалистская литература, не может быть со стопроцентной точностью передано с помощью более простого языка, остается очевидным, что при желании к этому идеалу можно приблизиться довольно сильно.

Переводу на более простой язык поддается, например, такая крайне герметичная дисциплина, как математика. В самом деле, в этой области знаний очень часто тоже ведется разговор о сущностях, которые крайне трудно «уловить» с помощью словаря других областей знания или повседневной жизни. Это, однако, не мешает математикам создавать язык своей дисциплины таким образом, чтобы любой заинтересованный человек мог через цепочку определений и разъяснений дойти от известных ему выражений до более эзотерических специальных терминов, вводимых специально для описания «глубинных» математических истин о реальности. Опять же, показательна разница во вторичной литературе - на этот раз учебной. При наличии огромного количества

4Если подлинные «глубинные» истины невыразимы в языке, то истины, формулируемые на языке экзистенциальной философии, должны, видимо, выступать своеобразной аппроксимацией к ним: самым большим, что мы можем сделать, чтобы передать их содержание в языке. 
учебников по множеству различных разделов математики, редкие учебники по экзистенциализму занимаются, в основном, тем, что перелагают учения корифеев, пользуясь их же языком и не предлагая ничего отдаленно похожего на цепочку определений, ведущую от простого языка к эзотерическому.

Таким образом, в случае истинности тезиса о невозможности переложения учения экзистенциализма на стандартный академический язык (назовем его для краткости «тезисом о непереводимости») мы имели бы беспрецедентную ситуацию, существенно отличную от того, как устроены дела в плане соотношения языков прочих специальных дисциплин и повседневного языка. Такого рода уникальность оказывается схожей с тем, как обычно описываются чудеса: в отличие от некоторого установленного закономерного хода вещей происходит нечто крайне редкое и нестандартное. Соответственно, отношение к тезису о непереводимости должно быть, по моему мнению, примерно таким же, как то, которое рекомендовал применительно к чудесам Дэвид Юм. Сообщениям о чудесах не следует верить до тех пор, пока не будут исчерпаны все естественные объяснения предполагаемых чудес.

На мой взгляд, существует как раз подходящее естественное объяснение нашему предполагаемому чуду - своеобразной лингвистической изолированности дискурса о «глубинных» истинах (и здесь мы переходим к содержательному возражению против этого дискурса). Объяснение видимости чуда носит, как это часто бывает, психологический характер и состоит в том, что разговор о «глубинных» истинах обычно является всего лишь разговором о собственных эмоциональных переживаниях. Чаще всего речь идет о переживаниях величественности, возвышенности или важности, сопровождающих когнитивные процессы, имеющие определенное содержание (такие, например, как размышления о собственной смерти). Тезис о непереводимости экзистенциализма на стандартный язык возникает как раз из-за того, что качественный аспект эмоиионального переживания почти не поддается словесному выражению. Таким образом, «глубинные» истины не являются особым содержанием мышления: скорее, некогнитивное переживание «глубинности» сопровождает мысли с некоторым обыкновенным типом содержания.

В случае правильности описанного типа эмотивизма относительно «глубинности» тезис о том, что язык не способен выразить содержание некоторой разновидности мыслей, теряет под собой основания, а интуиции, поддерживающие данный тезис, получают новую интерпретацию: 
«глубинность» есть результат реификации характера определенных эмоциональных процессов. По сравнению с прочими версиями эмотивизма и нонкогнитивизма, формулируемыми в отношении других предметных областей, эмотивистская трактовка «глубинности» сталкивается с гораздо меньшим количеством проблем, связанных с логико-лингвистическими особенностями соответствующего дискурса. Если язык морали, например, схож с языком других предметных областей до степени смешения (что делает возможной для него проблему Фреге-Гича), то специфический язык «глубинных» истин, как уже отмечалось, мало похож на «остальной» современный язык.

Подведем итог сказанному до сих пор. На мой взгляд, не существует никаких «глубинных» истин, которые могут открываться в чистом мышлении (а также никакого «просвета бытия», в котором можно было бы стоять или не стоять и т.д.). Существуют просто истины, или факты, и эти истины разными существами могут по-разному оцениваться с точки зрения их важности для этих существ. При наличии соответствующих когнитивных способностей осознание важности может проявляться в виде ярких эмоциональных переживаний, что вполне ожидаемо, в частности, для существ, имеющих эволюционную историю. Вполне ожидаемо, например, что для существ, способных предвидеть собственную смерть, этот факт часто кажется важным. Стоить заметить, что сказанное не означает отрицания существования внеприродных фактов, например, фактов морали. Даже в случае существования моральных фактов вопрос об их важности разными существами может «решаться» по-разному.

II

На мой взгляд, любая более-менее прямолинейная интерпретация вопроса «возможно ли мышление без языка?» предполагает ответ в интервале от осторожного «да» до категорического «да» ${ }^{5}$. Даже несмотря на то, что «мышление» и «язык» можно понимать по-разному, либо нагружая их философским содержанием, либо оставаясь более-менее в границах повседневного словоупотребления, подобрать здравую интерпретацию этих терминов, ведущую к отрицательному ответу на

5 Осторожное «да», в частности, появляется в тех ситуациях, в которых утверждается зависимость от языка приписываний «народных» интенциональных состояний, но признается зависимость самого языка от состояний ЦНС. 
поставленный вопрос, по-моему, весьма сложно. Можно, например, понимать «мышление» как внутреннюю речь или понимать «язык» как любую дискретную комбинаторную систему, но подобные интерпретации вряд ли относятся к числу здравых.

Отрицательный ответ легче получить, если отказаться от прямолинейной интерпретации вопроса о соотношении мышления и языка и интерпретировать его, например, в эпистемологическом ключе. Допустим, мы спрашиваем, можно ли эмпирически удостовериться в наличии у ныне живущего невербального земного животного того же самого набора психологических состояний (в частности, убеждений и желаний) со столь же разнообразным интенциональным содержанием - включающим в себя обобщения, а также репрезентации прошлого, самих себя, собственных психологических состояний и психологических состояний других существ,- какой есть у обычных взрослых людей 6 . Разумеется, эмпирические исследования почти ничего не могут подтвердить достоверно, а с учетом текущего состояния психологической науки (ср. кризис перепроверяемости) речь даже не идет о низких показателях $p$-значения. Но является ли интересной подобная эмпирическая интерпретация вопроса о возможности невербального мышления, особенно с учетом ссылки на ныне живущих земных животных? Обсуждая вопрос в такой интерпретации, мы, кажется, начинаем вести речь не столько о мышлении и языке, сколько о методологии научных исследований.

Учитывая неоднозначность интерпретаций, оптимальным подходом к решению проблемы соотношения мышления и языка я считаю трактовку этой проблемы как вторичной по отношению к проблеме природы интенциональности. Любая полноценная теория интенциональности должна предлагать решение проблемы соотношения мышления и языка в качестве следствия своих основных положений. Соответственно, если исходить из того, какие опции доступны сегодня на рынке серьезных теорий интенциональности, перспективы трактовки мышления как производной языка представляются туманными. Например, с точки зрения симпатичной мне телеосемантики одно и то же эволюционное

\footnotetext{
${ }^{6}$ Такой вопрос рассматривает в своей лекции Дж. Беннет и, подчеркивая существование альтернативных интерпретации психологических экспериментов, направленных на демонстрацию наличия у некоторых животных способности к формированию мыслей указанных типов, подводит читателя к отрицательному ответу на этот вопрос (Bennett, 1988).
} 
объяснение природы ментальных репрезентаций применимо, в принципе, как к людям, так и к невербальным животным, а значит роль языка ограничивается процессами коммуникации представителей отдельно взятого биологического вида. Действительно, учитывая общее эволюционное происхождение людей и животных, кажется крайне неправдоподобным, что должна существовать непреодолимая граница между их когнитивными способностями. Даже если ныне живущие представители невербальных биологических видов не имеют тех или иных присущих человеку когнитивных способностей (например, не способны думать о прошлом или репрезентировать психологические состояния), - что это говорит нам о соотношении мышления и языка? Вероятно, представители вымерших биологических видов имели эти когнитивные способности (быть может, например, человек умелый способен был думать о прошлом и т. д.), а если не имели, то могли бы существовать иные виды с этими способностями.

Любой сторонник сводимости мышления к языку должен, по-видимому, не только отрицать последний тезис о возможности существования невербальных биологических видов с присущими людям когнитивными способностями, но и настаивать, что язык является первичным носителем семантического содержания, так что мышление оказывается своего рода интериоризированным языком ${ }^{7},-$ в противном случае будет оставаться открытым вопрос о том, почему существование невербальных существ с человеческими способностями является невозможным. Ведь даже если мышление имеет структуру языка (гипотеза языка мысли), кажется, нет никакой необходимости в том, что некоторые существа вырабатывают в ходе эволюционного развития способность передавать содержание мыслей другим представителям своего сообщества, используя внешнюю комбинаторную знаковую систему, допускающую рекурсию. Разве невозможны существа, чья коммуникация не отражает структуры их мыслей (например, представляя собой набор ограниченного количества аналоговых сигналов)? В той мере, в какой к ним применима гипотеза языка мысли, такими существами как раз являются представители ныне живущих невербальных биологических видов.

${ }^{7}$ Н. Малкольм в характерной для эпохи лингвистического поворота статье о мышлении животных ограничивается еще более загадочной формулировкой, сравнивая соотношение языка и мышления с соотношением физического объекта и его отражения в зеркале (Malcolm, 1972). 
Сам по себе тезис о том, что язык является первичным носителем семантического содержания, сопряжен с рядом серьезных трудностей и проблем, пути устранения которых остаются, мягко говоря, неочевидными. Каким образом, например, происходит изучение ребенком своего родного языка, если у него предварительно отсутствуют психологические состояния с интенциональным содержанием? Все, что приходит на ум в данном случае - это павловские условные рефлексы, но таким способом трудно объяснить даже простейшую остенсию (разве для ассоциации выражения и предмета не требуется психологического состояния, обеспечивающего эту связь?), не говоря уж о таких свойствах языка, как систематичность и продуктивность. Аналогичная проблема касается феноменологии использования языка: что происходит, например, когда говорящий не может подобрать нужного слова, или когда переводчик размышляет о наиболее подходящем переводе некоторого термина? Без ссылки на особого рода психологические состояния говорящих (коммуникативные интенции) трудно объяснить прагматику языка: фактически, должен произойти коллапс дистинкции между семантикой и прагматикой. Но и с самой семантикой языка дела будут обстоять не очень просто. Несмотря на непрекращающиеся попытки эксплицировать витгенштейновский тезис о значении как употреблении, законченной строгой теории мы по-прежнему не имеем.

В связи с вопросом о соотношении мышления и языка имеется также самостоятельная интересная историко-философская проблема. Каким образом такая неправдоподобная, если не сказать безумная идея, как идея сводимости мышления к языку, могла пользоваться столь сильной популярностью в философии середины Хх в.? По моему мнению, это было обусловлено сочетанием двух исторических факторов. С одной стороны, не прошла бесследно эпоха «эпистемологического поворота», начатого философами Нового времени, пытавшимися порвать со схоластикой, подчеркивая важность поиска достоверного фундамента философского знания. С другой стороны, к этому времени уже потеряла популярность методологическая перспектива первого лица, поскольку, в частности, благодаря Расселу, в деталях проследившему последствия принятия данной перспективы, стал заметен возникающий радикальный разрыв с картиной мира здравого смысла. Язык приходит на смену «занавесу идей» в качестве универсального философского медиума, поскольку позволяет на этом этапе иметь «лучшее из обоих миров»: факты о языке известны нам примерно с той же достоверностью, с которой 
известны факты о сознании, но гораздо лучше согласуются с повседневными представлениями о мире. Проблема, разумеется, состоит в том, что трактовка метафизических вопросов в терминах некоторого предполагаемого фундамента философского знания часто искажает реальное положение вещей, так как эпистемологический приоритет не коррелирует с онтологическим. К счастью, подходящий для использования в рамках метафизических рассуждений метод вывода к лучшему объяснению позволяет отказаться от фундаменталистской редукции знания и отделить метафизические вопросы от эпистемологических. В частности, возвращаясь к нашей теме, существование независимого от языка мышления позволяет объяснить упомянутые в предыдущем абзаце процессы, и в отсутствие альтернативного объяснения без ссылки на мышление данный факт образует, с моей точки зрения, решающий аргумент в пользу первичности мышления перед языком ${ }^{8}$.

\section{ЛИТЕРАТУРА}

Bennett J. Thoughtful Brutes // Proceedings and Addresses of the American Philosophical Association. - 1988. - Vol. 62, no. 1. - P. 197-210.

Malcolm N. Thoughtless Brutes // Proceedings and Addresses of the American Philosophical Association. - 1972. - Vol. 46. - P. $5^{-20}$.

Zhdanov, S. M. [Zhdanov, S. M.] 2018. "Yazyk, myshleniye i 'glubinnyye istiny' [Language, Thought, and 'Profound Truths']" [in Russian]. Filosofiya. Zhurnal Vysshey shkoly ekonomiki [Philosophy. Journal of the Higher School of Economics] II (4), 107-115.

\section{Sergei Zhdanov \\ INDEPENDENT RESEARCHER \\ Language, Thought, and "Profound Truths"}

DOI: $10.17323 / 2587-8719-2018-I I-4-107-115$.

REFERENCES

Bennett, J. 1988. "Thoughtful Brutes." Proceedings and Addresses of the American Philosophical Association 62 (1): 197-210.

Malcolm, N. 1972. "Thoughtless Brutes." Proceedings and Addresses of the American Philosophical Association 46:5-20.

${ }^{8} Я$ благодарен Юлии Горбатовой за возможность еще раз обдумать важные и интересные философские вопросы, связанные с темой соотношения языка и мышления. 